\title{
Inhibition of Filarial Glutathione-S-transferase by various classes of compounds and their evaluation as novel antifilarial agents
}

\author{
R. AHMAD, A. K. SRIVASTAVA \\ Division of Biochemistry, P.O. Box No. 173, Central Drug Research Institute, Chattar Manzil Palace, \\ Lucknow-226001, India, Fax: +91-522-2623938, Tel.: +91-522-2612411-18 (Ext. 4346), \\ E-mail:drarv1955@yahoo.com
}

\begin{abstract}
Summary
Glutathione S-transferase(s); GST(s) (E.C. 2.5.1.18) are a large family of multifunctional dimeric enzymes that conjugate reduced glutathione to electrophilic centres in hydrophobic organic compounds. GST(s) represent the major class of detoxifying enzymes from parasitic helminths. The GST enzymatic activity has been described in the adult and larval stages of helminths. Several forms and isoforms of the enzyme have been purified and GST genes have also been isolated and expressed as recombinant proteins. The helminth GST(s) participate in detoxification of lipid hydroperoxides and cytotoxic carbonyl compounds produced by oxygen-reactive intermediates (ORIs). The ORIs can come from the endogenous parasite metabolism or from the host immune system. The helminth GST(s) are able to conjugate glutathione to xenobiotic compounds or to bind to the anthelminth drugs. GST is usually found to be localized near to host-parasite interface. This enzyme has been identified as a potentially vulnerable target in immunotherapy and chemotherapy of parasitic diseases. The most effective drug candidates are those based on inhibitors of GST. In the present study, purified GST from cytosolic fraction of bovine filarial worms Setaria cervi was inhibited in a concentration dependent fashion by various compounds such as hemin, ethacrynic acid, Shexylglutathione, quercetin, cibacron blue, lithocholate sulfate and ellagic acid. Cytosolic GST was inhibited to varying degrees by each inhibitor. In this context, the possible physiological significance of the observed results has been discussed.
\end{abstract}

Key words: Glutathione-S-transferase; enzyme inhibition; glutathione analog; Setaria cervi; helminth parasites; antiparasitic agents

\section{Introduction}

Glutathione-S-transferase(s); GST(s) (E.C. 2.5.1.18) are a multigene family of enzymes catalyzing the conjugation of glutathione with a large variety of xenobiotics as well as endogenous substrates. The main functions of these enzymes is to bring the substrate into close proximity with GSH by binding both GSH and electrophilic substrate (R-X) to the active site of the protein and activate the sulfhydryl group on GSH, thereby allowing the nucleophilic attack of GSH on the electrophilic substrate (R-X) (Armstrong, 1997). In GST(s) catalyzed reactions, the sulphur atom of GSH acts as nucleophilic substrate. The resulting GSH conjugate is then either excreted directly or further metabolized to yield a mercapturic acid (Meister \& Anderson, 1983). GST(s) catalyze various other reactions like nucleophilic aromatic substitution reactions, reversible Michael additions to $\alpha, \beta$-unsaturated aldehydes and ketones, isomerization, epoxide ring openings and for few GST(s), peroxidase reactions (Eaton \& Banunler, 1999; Salinas \& Wong, 1999). In addition to their isomerization and GSH conjugation activities, in mammals these enzymes contribute to defence against oxidative stress, by virtue of both their selenium-independent GSH peroxidase activities (Zhao et al., 1999). One prominent feature of GST is the presence of a number of isoenzymes in a given species (Mannervik \& Danielson, 1988). Kinetic properties such as inhibitor sensitivities and substrate specificities have been used to distinguish different GST isoenzymes. The GST enzyme family has been divided into a number of classes based on various criteria, such as amino acid/nucleotide sequence, immunological, kinetic and tertiary/quaternary structural properties (Sheehan et al., 2001). Eukaryotic GST(s) are currently arranged into 12 different classes: alpha, delta, epsilon, lambda, mu, omega, phi, pi, sigma, tau, theta and zeta as well as a mitochondrial kappa and a microsomal class (Gulick \& Fahl, 1995; Chelvanayagam et 
al., 2001; Sheehan et al., 2001; Marco et al., 2004; Hayes et al., 2005). Most well studied species have been shown to have genes for several of these GST classes, although some classes are still considered to be taxon-specific (e.g. phi, tau and lambda have been found only in plants whereas delta and epsilon only in insects).

These enzymes exist as dimeric proteins comprised of two subunits (Cnubben et al., 2001). Each of the subunits possesses a glutathione-binding site ( $\mathrm{G}$ site) as well as an adjacent relatively hydrophobic site for the binding of the electrophilic substrate. In addition, in various isoenzymes (alpha and pi class) a non-substrate binding site has been recognized, which may function as a transport site or a regulatory site (van Bladeren, 2000).

Inhibition of GST(s) is important from several points of view. These involve applications in studies of the catalytic mechanism, e.g. studying the topological and binding characteristics of the active site. Also, from a therapeutic point of view, inhibition of GST(s) steadily becomes more interesting, since these enzymes appear to be involved in drug resistance and in the biosynthesis of a number of important arachidonic acid metabolites such as prostaglandins and leukotrienes (van Bladeren \& Ommen, 1991). Modulation of the GST activity could be used to regulate the concentrations of these compounds. Towards this end, many research groups have been pursuing the development of GST inhibitors for more than a decade (Flatgaard et al., 1993; Lyttle et al., 1994; Morgan et al., 1996; Lyon et al., 2003). Also, because of its role in protecting cells against immune mediated lipid peroxidation, inhibition of GST offers the possibility of combining immuno- and chemotherapy. In diagnostic medicine, as well as in antiparasitic drug development, GST inhibitors are important lead molecules (Mathew et al., 2006).

Glutathione metabolism represents a potential target for antiparasite drug design. GST, an important enzyme of GSH cycle, is considered to be an essential detoxification enzyme in parasitic species. The interest in helminth GST(s) stems from the fact that they represent the major detoxification enzymes in these organisms and consequently represent important pharmacological and immunological targets (Morrison et al., 1996). As helminths contain very low levels of other detoxification enzymes such as catalase, superoxide dismutase (SOD) and cytochrome P450, GST(s) may provide the worm's primary defense against electrophilic and oxidative damage (Brophy \& Barrett, 1990). Primary amino acid sequence alignment of helminth GST(s) with mammalian GST(s) indicates that non-mammalian GST(s) superfamilies are represented in these parasites. Helminth GST(s), though present as isoenzymes, fail to show a clear biochemical homology to any of the three main mammalian GST families (O’Leary \& Tracy, 1988; Brophy \& Barrett, 1990). Thus, inhibition of helminth GST(s) by compounds may be advantageous from the host's point of view as their inhibition deprives the parasites of their major defense against oxidative stress and makes them unable to survive. In the present work we have investigated the relative susceptibi- lity of GST from bovine filarial worms Setaria cervi to inhibition by various classes of mammalian GST inhibitors.

\section{Materials and Methods}

\section{Materials}

Reduced glutathione (GSH), trizma, ethylene diamine tetra acetic acid (EDTA), potassium chloride $(\mathrm{KCl})$, sodium chloride $(\mathrm{NaCl})$, hemin, ethacrynic acid (EA), S-hexylglutathione, quercetin, cibacron blue (CB), lithocholate sulfate (LS), ellagic acid and bovine serum albumin (BSA) were purchased from Sigma Chemical Co., USA. 1-chloro-2, 4dinitrobenzene (CDNB) was from Spectrochem Pvt. Ltd. Mumbai, India. Folin \& Ciocalteu's phenol reagent was purchased from Sisco Research Laboratories, Mumbai, India. Hanks balanced salt solution (HBSS) was from Himedia laboratories Pvt. Ltd. Mumbai, India. All other chemicals used were of analytical grade.

\section{Filarial worms}

In view of the practical difficulties in procuring human strains of Wuchereria bancrofti and Brugia malayi, the bovine filarial parasite $S$. cervi, resembling the human species in having microfilarial periodicity and chemotherapeutic response to known antifilarial agents, was chosen as a model for conducting enzymatic studies.

\section{Collection of filarial worms $S$. cervi}

Adult bovine filarial worms $S$. cervi females of average body weight $35 \pm 5 \mathrm{mg}$ and length $6.0 \pm 1.0 \mathrm{~cm}$ were collected from the peritoneal cavity of freshly slaughtered naturally infected water buffaloes Bubalus bubalis (Linn.) at a local abattoir. They were thoroughly washed with saline and kept in Hanks balanced salt solution with sodium bicarbonate and glucose $(5.55 \mathrm{mM})$ for $60 \mathrm{~min}$ at $37{ }^{\circ} \mathrm{C}$ in a Dubnoff metabolic shaker for complete revival before being used in enzymatic studies.

\section{Preparation of GST from $S$. cervi}

A $10 \%$ homogenate of filarial worms $S$. cervi was prepared in $50 \mathrm{mM}$ Tris- $\mathrm{HCl}$ buffer, $\mathrm{pH} 7.4$ containing $250 \mathrm{mM}$ sucrose and $0.2 \mathrm{mM}$ EDTA using a Potter Elvehjem glass homogenizer fitted with a Teflon pestle. The homogenate was centrifuged at $1,000 \mathrm{~g}$ for $15 \mathrm{~min}, 10,000 \mathrm{~g}$ for $30 \mathrm{~min}$ and subsequently at $100,000 \mathrm{~g}$ for $60 \mathrm{~min}$ to obtain mitochondrial, post mitochondrial, cytosolic and microsomal fractions respectively.

Each fraction was dialyzed against 100 volumes of $20 \mathrm{mM}$ potassium phosphate, $\mathrm{pH} 7.4$ containing $0.2 \mathrm{mM}$ EDTA and dialyzed preparation was used as enzyme source.

\section{GST activity determination}

GST activity in various dialyzed fractions obtained as a result of subcellular fractionation was determined spectrophotometrically at $340 \mathrm{~nm}$ according to the method of Habig et al. (1974). All reactions were corrected for nonenzymatic conjugation, with reaction mixtures without 
enzyme serving as controls.

Under standard assay conditions, the reaction mixture contained $100 \mathrm{mM}$ phosphate, $\mathrm{pH} 6.5,1.0 \mathrm{mM}$ CDNB in $20 \mu$ ethanol, $1.0 \mathrm{mM} \mathrm{GSH}$ and $25 \mu$ l enzyme preparation containing at least $62.50 \mu \mathrm{g} \pm 0.025$ protein unless stated otherwise. A unit of enzyme activity was expressed as the amount that catalyzes the formation of $1 \mu \mathrm{mol} \mathrm{S-2,4-dinit-}$ rophenyl-GSH adduct per minute, using a molar extinction coefficient of $9.6 \mathrm{mM}^{-1} \mathrm{~cm}^{-1}$ for CDNB. Protein was estimated by the method of Lowry et al. (1951) using BSA as standard.

\section{Purification of GST from S. cervi}

In the standardized protocol, purification was carried out by the preparation of the homogenate, salt precipitation of the cytosolic fraction, ultrafiltration, ion exchange chromatography and affinity chromatography on GSH-Sepharose. The GSH affinity column was prepared according to the method of Simons and Vander Jagt (1977). Native PAGE was performed on a $7.5 \%$ gel according to the method of Laemmli, (1970). Gels were stained for GST activity after native PAGE using the method of Ricci et al. (1984). GST purification was optimized by inclusion of relatively fewer steps to get a better yield of the enzyme. The homogeneity of the purified protein was confirmed by SDS-PAGE analysis and MALDI TOF studies. Two-dimensional electrophoresis of the purified GST yielded a single spot thereby suggesting that $S$. cervi has only a single GST (results not shown).

\section{Inhibition studies}

In order to determine dose-dependent effect of various inhibitors and their respective inhibitor constants $\left(\mathrm{K}_{\mathrm{i}}\right)$, the purified enzyme was incubated with varying concentrations of inhibitor for $10 \mathrm{~min}$ at room temperature in the presence of $100 \mathrm{mM}$ potassium phosphate buffer and 1.0 $\mathrm{mM}$ GSH. The reaction was initiated by the addition of 1.0 $\mathrm{mM}$ CDNB and the absorbance at $340 \mathrm{~nm}$ was monitored for $5 \mathrm{~min}$ at $30 \mathrm{sec}$ intervals. The percentage inhibition of the enzyme activity by various inhibitors was calculated by comparing with a control tube. Decrease in enzyme activity in presence of varying concentrations of inhibitors as compared to control was expressed as $\mu \mathrm{mol} \mathrm{S}-2,4$-dinitrophenyl-GSH adduct formed/min \pm S.D. based on experiments done in quadruplicates.
For determining the type of inhibition of $S$. cervi GST with respect to GSH and CDNB by a particular inhibitor, the purified cytosolic enzyme was incubated with varying concentrations of inhibitors at different concentrations of one substrate for $10 \mathrm{~min}$ at room temperature in the presence of $100 \mathrm{mM}$ potassium phosphate buffer while keeping the concentration of the other substrate fixed. The reaction was initiated by addition of CDNB and the absorbance at $340 \mathrm{~nm}$ was monitored for $5 \mathrm{~min}$ at $30 \mathrm{sec}$ intervals.

In order to determine $\mathrm{IC}_{50}$ values (inhibitor concentration at which enzyme inhibition was $50 \%$ ) of various inhibitors and their respective inhibitor constants $\left(\mathrm{K}_{\mathrm{i}}\right)$, enzyme was incubated with varying concentrations of inhibitor for 10 min at room temperature in the presence of $100 \mathrm{mM}$ potassium phosphate buffer and $1.0 \mathrm{mM} \mathrm{GSH}$. The reaction was initiated by the addition of $1.0 \mathrm{mM}$ CDNB and the absorbance at $340 \mathrm{~nm}$ was monitored for $5 \mathrm{~min}$ at $30 \mathrm{sec}$ intervals. The percentage inhibition of the enzyme activity by various inhibitors was calculated by comparing with control tube.

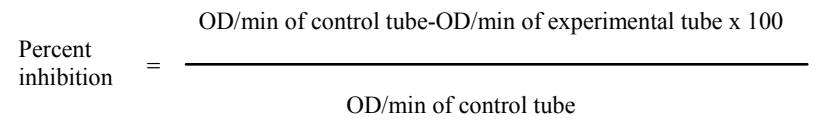

\section{Results}

Table 1 depicts the distribution of GST activity in various subcellular fractions of $S$. cervi homogenate. It is evident from the results that GST activity in these worms was also mainly associated with the cytosolic fraction, which was used as source for enzyme purification. Tetrapyrroles (bilirubin, biliverdin, chlorophyllin and hemin) are known inhibitors of GST. Cholrophyllin and hemin are the most effective in inhibiting the activity of GST whereas bilirubin and biliverdin are the least effective. Thus, the degree of inhibition is related to whether the tetrapyrroles are closed or open chain compounds. Cholrophyllin and hemin are closed chain tetrapyrroles whereas bilirubin and biliverdin are open chain tetrapyrroles. Ferriprotoporphyrin IX chloride (hemin), a known inhibitor of mammalian GST inhibited $S$. cervi GST in a concentration dependent fashion when studied for its effect in the 10 to $50 \mu \mathrm{M}$ range. It maximally inhibited GST to around $92.4 \%$ at $50 \mu \mathrm{M}$

Table 1. Subcellular distribution of GST activity in filarial worms $S$. cervi

\begin{tabular}{|c|c|c|c|}
\hline Fraction & $\begin{array}{c}\text { Total activity* } \\
(\mu \mathrm{mol} / \mathrm{min})\end{array}$ & $\begin{array}{c}\text { Total protein } \\
(\mathbf{m g})\end{array}$ & $\begin{array}{c}\text { Specific Activity** } \\
(\mu \mathrm{mol} / \mathrm{min} / \mathrm{mg} \text { protein) }\end{array}$ \\
\hline Crude homogenate & $1.40 \pm 0.090$ & $20.1 \pm 0.152$ & $0.070 \pm 0.0185$ \\
\hline Mitochondrial fraction & 0 & $1.25 \pm 0.080$ & Not detectable \\
\hline Post mitochondrial fraction & $1.20 \pm 0.042$ & $18.2 \pm 0.056$ & $0.066 \pm 0.017$ \\
\hline Cytosolic fraction & $2.024 \pm 0.018$ & $13.9 \pm 0.033$ & $0.122 \pm 0.024$ \\
\hline Microsomal fraction & $0.026 \pm 0.02$ & $2.54 \pm 0.025$ & $0.010 \pm 0.0052$ \\
\hline
\end{tabular}

\footnotetext{
*Activity was expressed as $\mu \mathrm{mol} \mathrm{S-2,4-dinitrophenyl-GSH}$ adduct formed/min \pm S.D. based on experiments done in quadruplicates. ** Specific Activity was expressed as $\mu \mathrm{mol} \mathrm{S-2,} \mathrm{4-dinitrophenyl-GSH} \mathrm{adduct} \mathrm{formed} / \mathrm{min} / \mathrm{mg}$ protein \pm S.D. based on experiments done in quadruplicates.
} 

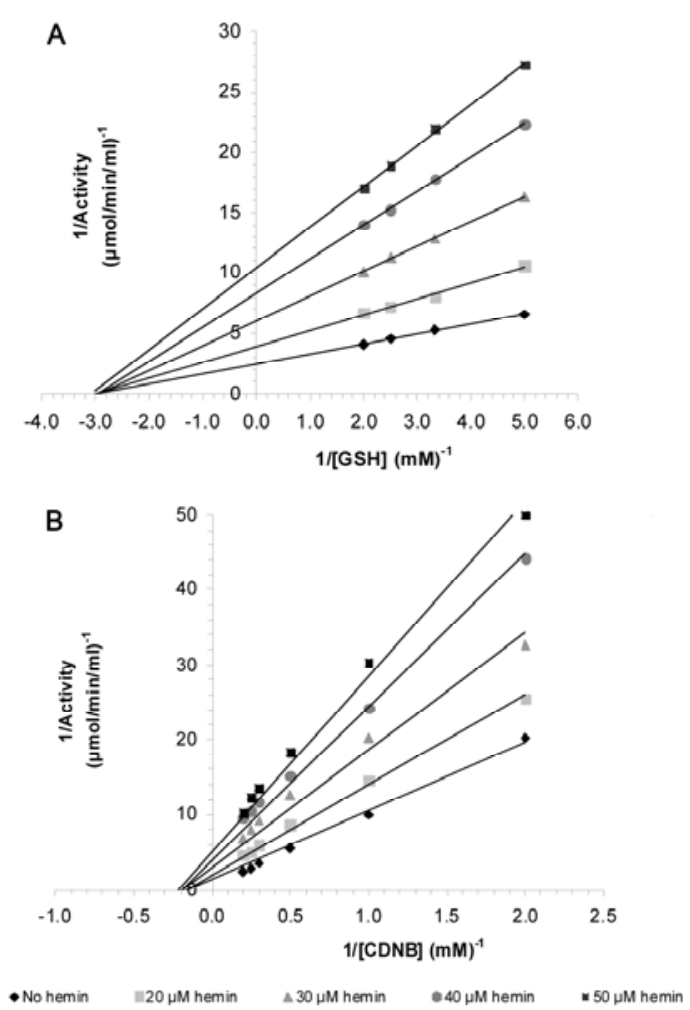

Figure 1. Type of inhibition on the activity of purified GST from $S$. cervi with respect to GSH (A) and/or CDNB (B) by hemin.

Decrease in enzyme activity in the presence of varying concentrations of inhibitor as compared to control was expressed

as $\mu \mathrm{mol} \mathrm{S-2,} \mathrm{4-dinitrophenyl-GSH} \mathrm{adduct} \mathrm{formed/min} \pm$ S.D. based on experiments done in quadruplicates.

and was therefore found to be a potent inhibitor of $S$. cervi GST. Figures 1a and b depict the GST catalyzed conjugation of GSH to CDNB in the presence and absence of hemin. Table 2 depicts the $\mathrm{IC}_{50}$ value and apparent $\mathrm{K}_{\mathrm{i}}$ of the enzyme with respect to hemin.

The phenoxy acetic acid diuretic, ethacrynic acid, also inhibited $S$. cervi GST activity in a concentration dependent fashion when studied for its effect in the concentration range 2.0 to $40 \mu \mathrm{M}$. It maximally inhibited GST to around $72.1 \%$ at $40 \mu \mathrm{M}$. Figures $2 \mathrm{a}$ and $\mathrm{b}$, respectively depict the pattern of inhibition of the enzyme with respect to substrates GSH and CDNB by ethacrynic acid. Table 2 gives the $\mathrm{IC}_{50}$ value and $\mathrm{K}_{\mathrm{i}}$ value of the enzyme with respect to ethacrynic acid.

The GSH analog $S$-hexylglutathione inhibited purified GST from $S$. cervi in a concentration dependent manner when studied for its effect in the concentration range 0.025 to $0.2 \mathrm{mM}$. It maximally inhibited GST to around $90.2 \%$ with respect to substrate GSH (Figure 3).

The flavonoid inhibitor quercetin also inhibited $S$. cervi GST activity in a concentration dependent fashion when studied for its effect in the concentration range 10 to $50 \mu \mathrm{M}$. GST was maximally inhibited to around $82 \%$ at $50 \mu \mathrm{M}$ concentration of quercetin.

The dye cibacron blue (CB) inhibited the purified enzyme in a concentration dependent fashion in the concentration range 0.0125 to $0.25 \mu \mathrm{M}$. Maximum inhibition on GST activity was around $92.5 \%$.

Bile acid lithocholate sulfate (LS) inhibited cytosolic GST from $S$. cervi within the concentration range $0.1-1.0 \mathrm{mM}$ with a maximum inhibition of $90.3 \%$.

The antioxidant plant phenol ellagic acid exhibited a maximum inhibition of $78.1 \%$ on purified cytosolic GST activity when studied in the concentration range $0.1-1.5 \mu \mathrm{M}$. Of all inhibitors tested, hemin was found to be a potent inhibitor of $S$. cervi GST. Further studies into the structure and binding properties of hemin to GST may be of critical importance for the development of therapeutic agents.

\section{Discussion}

A large variety of inhibitors of GST(s) from mammalian sources are known. Some of these are strong and selective enough to be used to characterize individual isoenzymes

Table 2. $\mathrm{K}_{\mathrm{i}}$ and $\mathrm{IC}_{50}$ values of standard GST inhibitors with respect to cytosolic GST from S. cervi

\begin{tabular}{cccc}
\hline Inhibitor & Class & $\mathbf{K}_{\mathbf{i}}$ value & IC $_{\mathbf{5 0}}$ value \\
\hline Hemin & porphyrin & $4.0 \pm 0.08 \mu \mathrm{M}$ & $25.0 \pm 0.03 \mu \mathrm{M}$ \\
Ethacrynic acid & Substituted phenoxy acetic acid & $22 \pm 0.125 \mu \mathrm{M}$ & $15 \pm 0.110 \mu \mathrm{M}$ \\
S-hexylglutathione & GSH analog & $0.04 \pm 0.01 \mathrm{mM}$ & $0.1 \pm 0.008 \mathrm{mM}$ \\
Quercetin & Flavone derivative & $5.0 \pm 0.05 \mu \mathrm{M}$ & $25 \pm 0.15 \mu \mathrm{M}$ \\
Cibacron blue-3GA & Dye & $0.02 \pm 0.006 \mu \mathrm{M}$ & $0.025 \pm 0.01 \mu \mathrm{M}$ \\
Lithocholate sulfate & Bile acid & $0.1 \pm 0.005 \mathrm{mM}$ & $0.3 \pm 0.002 \mathrm{mM}$ \\
Ellagic acid & Substituted lactone derivative & $0.27 \pm 0.004 \mu \mathrm{M}$ & $0.8 \pm 0.002 \mu \mathrm{M}$
\end{tabular}

$\mathrm{K}_{\mathrm{i}}$ and $\mathrm{IC}_{50}$ value were calculated by measuring enzyme activity in the presence of varying concentrations of inhibitors as $\mu \mathrm{mol} \mathrm{S-2,4-dinitrophenyl-GSH}$ adduct formed/min \pm S.D. based on experiments done in quadruplicates 

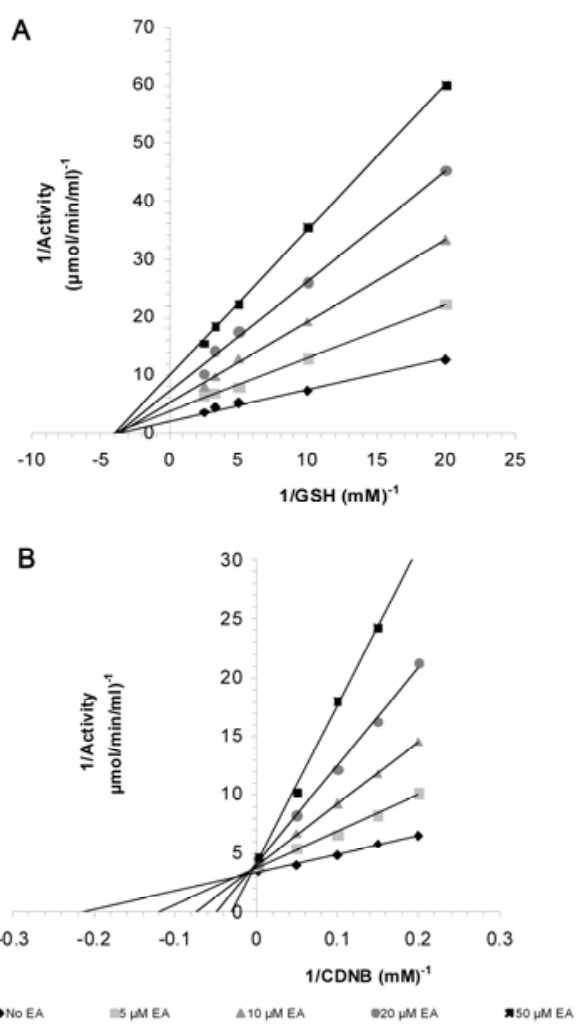

Figure 2. Type of inhibition on the activity of purified GST from $S$. cervi with respect to GSH (A) and/or CDNB (B) by EA.

Decrease in enzyme activity in the presence of varying concentrations of inhibitor as compared to control was expressed

as $\mu \mathrm{mol} \mathrm{S-2,4-dinitrophenyl-GSH}$ adduct formed $/ \mathrm{min} \pm$ S.D. based on experiments done in quadruplicates.

(Mannervik, 1985). GST inhibitors that are relatively nontoxic, isoenzyme specific and active in vivo have not yet been developed. Despite a considerable effort, so far the only in vivo active inhibitors of GST(s) are ethacrynic acid and a number of glutathione derived structures (Morgan et al., 1996; Mulder \& Ouwerkerk-Mahadevan, 1997). A number of inhibitors have been reported that are suitable for in vitro studies. These include ethacrynic acid, the antibiotic calvatic acid, curcumin, haloenol lactone, disulfiram and organotin compounds, to name just a few (Morgan et al., 1996; van Iersel et al., 1996, 1997).

The currently existing GST inhibitors tend to fall into three classes, determined by their binding site on the protein and mechanism of inhibition. The first of these are analogs of electrophilic substrates that bind in the hydrophobic region of the active site (H-site) and competitively inhibit the binding of hydrophobic electrophiles. Second are glutathione conjugates which occupy both the glutathione binding site (G-site) and at least part of the $\mathrm{H}$-site and are typically competitive with respect to both GSH and hydrophobic substrate. Third, a collection of compounds referred to as nonsubstrate ligands are non-competitive inhibitors of GST(s). These inhibitors are typically hydrophobic anions and include endogenous compounds such as porphyrins and bile acids and such exogenous compounds as sulfated organic dyes. The binding site of this group of inhibitors has historically been called the ligandin site and its loca- tion remains uncertain; however, it may lie at one edge of the H-site or within the wide cleft between the two subunits of the GST dimer. These nonsubstrate ligands are unique among the GST inhibitors in that they elicit noncompetitive inhibition with respect to both GSH and electrophilic substrate.

The cytosolic enzyme from $S$. cervi exhibited inhibition with various inhibitors used to distinguish the mammalian GST families but showed no clear biochemical relationship to any one mammalian GST class. Although class-distinguishing substrates and inhibitors are useful, it has been demonstrated that isolated GST(s) have overlapping substrate specificities and no single compound can give an unambiguous distinction (Mannervik et al., 1985). The inhibitor profile of $S$. cervi GST showed a limited relationship to the profile of mammalian GST(s) (Stockman et al., 1987). The inhibitor profile of $S$. cervi GST is similar to that described for the Schistosoma mansoni (Sm28) GST (Walker et al., 1993), O. volvulus GST (OvGST2) (Liebau et al., 1996) and GST from Ascaris suum (Liebau et al., 1997). From the perspective of classification, it is interesting that, whereas helminth organisms express GST(s) that are clearly related to mu, pi and sigma classes of other organisms, these enzymes contain sufficient regions of structural difference compared with host enzymes to hold out the prospect of development of parasite-specific vaccines.

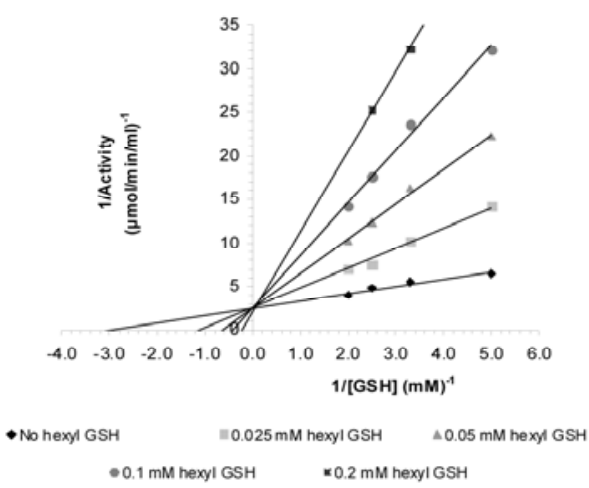

Figure 3. Type of inhibition on the activity of purified GST from $S$. cervi with respect to CDNB by hexylglutathione. Decrease in enzyme activity in the presence of varying concentrations of inhibitor as compared to control was expressed as $\mu \mathrm{mol} \mathrm{S-2,4-}$ dinitrophenyl-GSH adduct formed/min \pm S.D. based on experiments done in quadruplicates.

Central to the whole concept of chemotherapy is selectivity, the drug must affect the parasite, but not the host, although this can sometimes be very difficult to achieve. The continuing demand for new antiparasitic agents has always encouraged an ever-widening search for novel biochemical targets that can provide a basis for rational drug development. GST is therefore a tempting target both for chemotherapy and for vaccine development of filarial infections.

In general, helminth GST(s) are inhibited, as are mammalian GST(s), by a multitude of ligands from hematin to fatty acids. Helminth GST(s) appear to bind a range of hydrophobic ligands, including hematin related com- 
pounds, bile acids, unsaturated fatty acids and plant phenols. Binding could also be a passive detoxification mechanism, as has been suggested for the interaction of hematin with $S$. japonicum GST (Smith et al., 1986). This may indicate that, as proposed for a number of mammalian hepatic GST(s) (Ketterer et al., 1988), helminth GST(s) are general binding proteins involved in the transport of hydrophobic ligands. Cestodes and digeneans have relatively high levels of GST, which provides high number of mobile hydrophobic binding sites that could aid the uptake of ligands required for intracellular metabolism. The inhibition of cestode GST(s) by ligands such as bile acids and unsaturated fatty acids suggests that these ligands may modulate the activity of the enzymes in vivo. Helminth GST(s) could also be intracellular receptors for bile acids. A variation in the inhibitor profile between human and parasitic GST(s) is more common than selective inhibition. For example, the major GST(s) from cestodes and S. mansoni are relatively more sensitive to inhibition to cibacron blue and triphenyltin chloride compared to the majority of mammalian GST(s) (Brophy and Barrett, 1990). Inhibition of $\mathrm{OvGST} 2$ has been demonstrated at low micro molar concentration for these conjugates and selectivity for $O v$ GST over human pi GST of greater than 10-fold has been obtained (Brophy et al., 2000).

The potential of GST as a drug target has previously been studied by studying the in vitro effects of some known GST inhibitors on the motility and viability of $S$. cervi adults and microfilariae (mf). Of all those tested, ethacrynic acid (EA), N-ethyl malemide (NEM), 4-nitropyridine oxide and 1-chloro-2, 4-dinitrobenzene (CDNB) at micromolar concentrations reduced the viability and motility of mf, third stage larvae (L3) and adult worms. These results suggest that GST(s) are major metabolic enzymes and may play an important role in the parasite's survival (Rao et al., 2000). Among the GST inhibitors studied, butylated hydroxyanisole (BHA) markedly reduced worm viability; compounds in this chemical series may have therapeutic use (Gupta \& Rathaur, 2005).

If the present strategy i.e. inhibition of parasitic GST, affects the survival of the parasites or helps in the enhancement of activity of presently available antifilarial/antimalarial drugs, it will help in the design of new target based chemotherapeutic agents. The difference in the extent of inhibition of GST activities of the parasite and the host by the inhibitors tested in the present study indicates that these inhibitors have the potential to emerge as lead molecules for further exploration to develop new class of antifilarial/antimalarial drugs. Moreover, it has been suggested that perhaps it is not essential to target the parasite's enzymes specifically as it might be feasible simply to take advantage of the extreme sensitivity of parasite to oxidative damage (Lüersen et al., 1998).

In future, pro-drug design could provide a route to parasite GST inhibition. This inhibitory mechanism could create selectivity by mimicking putative in vivo substrates of parasites GST(s), i.e. carbonyl products of immune-mediated lipid peroxidation. The conjugates of glutathione and cytotoxic carbonyls are potent inhibitors of cestode and digenean GST(s). This will enhance our understanding of detoxification processes, drug resistance and drug action in the parasite and will open new avenues for the development of antiparasitic agents.

\section{Acknowledgements}

Financial assistance from Council for Scientific and Industrial Research (CSIR), New Delhi (India) in the form of Senior Research Fellowship to RA is gratefully acknowledged.

\section{References}

ARMSTRONG, R. N. (1997): Structure, catalytic mechanism and evolution of the glutathione-S-transferase(s). Chem. Res. Toxicol., 10: $2-18$

BROPHY, P. M., BARRETT, J. (1990): Glutathione-S-transferase in helminths. Parasitol., 100: 345 - 349

Brophy, P. M., CAmpbell, A. M., Van Eldick, A. J., Teesdale-Spittle, P. H., Liebau, E., Wang, M. F. (2000): $\beta$-Carbonyl substituted glutathione conjugates as inhibitors of O. volvulus GST2. Bioorg. Med. Chem. Lett., 10: $979-981$

Chelvanayagam, G., Parker, M. W., Board, P. G. (2001): Fly fishing for GST(s): a unified nomenclature for mammalian and insect glutathione-S-transferase(s). Chem. Biol. Interact., 133: $256-260$

Cnubben, N. H. P., Rietjens, I. M. C. M., Wortelboer, H., Van Zanden, J., Van Bladeren, P. J. (2001): The interplay of glutathione-related processes in antioxidant defense. Environ. Toxicol. Pharmacol., 10: 141 - 152

EAtON, D. L., BANunLER, T. K. (1999): Concise review of glutathione-S-transferase(s) and their significance to toxicology. Toxicol. Sciences, 49: 156-164

FlatgaArd, J. E., Bauer, K. E., Kauvar, L. M. (1993): Isozyme specificity of novel glutathoine-S-transferase inhibitors. Cancer Chemother. Pharmacol., 33: 63 - 70

GULICK, A. M., FAHL, W. E. (1995): Mammalian glutathione-S-transferase: regulation of an enzyme system to achieve chemotherapeutic efficacy. Pharmac. Ther., 66: $237-257$

GuPTA, S., RATHAUR, S. (2005): Filarial glutathione-Stransferase: its induction by xenobiotics and potential as drug target. Acta Biochimica Polonica, 52: 493 - 500

HABIG, W. H., PABSt, M. J., JAKOBY, W. B. (1974): Glutathione-S-transferase(s): the first enzymatic step in mercapturic acid formation. J. Biol. Chem., 249: 7130 - 7139

Hayes, J.D., Flanagan, J. U., Jowsey, I. R. (2005): Glutathione-S-transferase(s). Ann. Rev. Pharmacol. Toxicol., 45: $51-88$

Ketterer, B., Meyer, D. J., Clark, A. G. (1988): Glutathione Conjugation: Its Mechanisms and Biological Significance. In: Sies, H. and Ketterer, B. (Eds). Academic Press, London

LAEMMLI, U. K. (1970): Cleavage of structural proteins during the assembly of the head of bacteriophage T4. $\mathrm{Na}$ - 
ture, 227: $680-685$

Liebau, E., WildenburG, G., Brophy, P. M., Walter, R. D., HenKle-Duhrsen, K. (1996): Biochemical analysis, gene structure and localization of the $24 \mathrm{kDa}$ glutathioneS-transferase from Onchocerca volvulus. Mol. Biochem. Parasitol., 80: 27 - 39

Liebau, E., Eckelt, V. H. O., Wildenburg, G., Teesdale-Spittle, P. H., Brophy, P. M., Walter, R. D., HENKLE-DuHRSEN, K. (1997): Structural and functional analysis of a glutathione-S-transferase from Ascaris suum. Biochem. J., 324: $659-666$

LOWry, O. H., Rosebrough, N. J., FARR, A. L., RANDALl, R. J. (1951): Protein measurement with the Folin phenol reagent. J. Biol. Chem., 193: 265 - 276

LÜERSEN, K., WALter, R. D. AND Müller, S. (1998): The putative $\gamma$-glutamylcysteine synthetase from Plasmodium falciparum contains large insertions and a variable tandem repeat. Mol. Biochem. Parasitol., 98: 131 - 142.

LyON, R. P., Hill, J. J., ATKIns, W. M. (2003): Novel class of bivalent glutathione-S-transferase inhibitors. Biochem., 42: $10418-10428$

Lyttle, M. H., Hocker, M. D., Hui, H. C., Caldwell, C. G., Aaron, D. T., EngQvist-Goldstein, A., FlatgaARd, J. E., BAUER, K. E. (1994): Isozyme-specific glutathione-Stransferase inhibitors: design and synthesis. J. Med. Chem., 37: $189-194$

MANNERVIK, B., DANIELSON, U. H. (1988): Glutathione-Stransferase(s): structure and catalytic activity. CRC Crit. Rev. Biochem., 23: $283-337$

MANNERVIK, B. (1985): The isoenzymes of glutathione-Stransferase. Adv. Enzymol., 57: 357 - 417

Marco, A., Cuesta, A., Pedrola, L., Palau, F., Martin, I. (2004): Evolutionary and structural analyses of GDAP1, involved in Charcot-Marie-Tooth disease, characterize a novel class of glutathione-S-transferase-related genes. $\mathrm{Mol}$. Biol. Evol., 21: 176 - 187

Mathew, N., Kalyanasundaram, M., Balaraman, K. (2006). Glutathione-S-transferase inhibitors. Expert Opinion on Therapeutic Patents, 16: 431 - 444

Meister, A., Anderson, M. E. (1983): Glutathione. Ann. Rev. Biochem., 52: $711-760$

Morgan, A. S., Ciaccio, P. J., Tew, K. D., Kauvar, L. M. (1996): Isozyme-specific glutathione-S-transferase inhibitors potentiate drug sensitivity in cultured human tumor cell lines. Cancer Chemother. Pharmacol., 37: 363 - 370

Morrison, C. A., Colin, T., Sexton, J. L., Bowen, F., Wicker, J., Friedel, T., SPITHILl, T. W. (1996): Protection of cattle against Fasciola hepatica infection by vaccination with glutathione-S-transferase. Vaccine, 14: $1603-1612$

Mulder, G. J., OUWERKERK-MAHAdEVAN, S. (1997): Modulation of glutathione conjugation in vivo: how to decrease glutathione conjugation in vivo or in intact cellular systems in vitro. Chem. Biol. Interact., 105: 17 - 34 O'LEARY, K. A., TRACY, J. W. (1988): Purification of free cytosolic glutathione-S-transferase(s) from adult Schisto-

RECEIVED MAY 4, 2007 soma mansoni. Arch. Biochem. Biophys., 264: 1 - 12

RaO, U. R., SAlinas, G., MeHta, K., Klei, T. R. (2000): Identification of glutathione-S-transferase as a potential target enzyme in Brugia species. Parasitol. Res., 86: 908 915

Ricci, G., Bello, M. L., Caccuri, A. M., Galiazzo, F., FEDERICI, G. (1984). Detection of glutathione-S-transferase activity on polyacrylamide gels. Anal. Biochem., 143: 226-230

Salinas, A. E., Wong, M. G. (1999): Glutathione-Stransferase(s): a review. Curr. Med. Chem., 6: 279 - 309

Sheehan, D., Meade, G., Foley, V. M., Dowd, C. A. (2001): Structure, function and evolution of glutathione-Stransferase(s): implications for classification of nonmammalian members of an ancient enzyme superfamily. Biochem. J., 360: 1 - 16

Simons, P. C., VAnder Jagt, D. L. (1977): Purification of GST(s) from human liver by glutathione affinity chromatography. Anal. Biochem., 82: $334-341$

Smith, D. B., Davern, K. M., BoArd, P. G., TiU, W. U., GARCiA, E. G., Mitchell, G. F. (1986): M 26,000 antigen of Schistosoma japonicum recognized by resistant WEHI/129J mice is a parasite glutathione-S-transferase. Proc. Nat. Acad. Sci. USA, 83: $8703-8707$

Stockman, P. K., Mclellan, L. I., Hayes, J. D. (1987): Characterization of the basic glutathione-S-transferase $B_{1}$ and $\mathrm{B}_{2}$ subunits from human liver. Biochem. J., 244: 55 61

VAn Bladeren, P. J., OMmen, B. V. (1991): The inhibition of glutathione-S-transferase(s): mechanisms, toxic consequences and therapeutic benefits. Pharmacol. Ther., 51, 35-46

VAN BLADEREN, P. J. (2000): Glutathione conjugation as bioactivation reaction. Chem. Biol. Interact., 129: 1 - 76

Van Iersel, M. L., Ploemen, J. P., Struik, I., VAN Amersfoort, C., Keyzer, A.E., Schefferlie, J. G., VAN Bladeren, P. J. (1996): Inhibition of glutathione-Stransferase activity in human melanoma cells by alpha, beta- unsaturated carbonyl derivatives: effects of acrolein, cinnamaldehyde, citral, crotonaldehyde, curcumin, ethacrynic acid and trans-2-hexenal.Chem. Biol. Interact., 102: $117-132$

Van Iersel, M. L., Ploemen, J. P., Lo Bello, M., FEDERICI, G., VAN BLADEREN, P. J. (1997): Interactions of alpha, beta- unsaturated aldehydes and ketones with human glutathione-S-transferase P1-1.Chem. Biol. Interact., 108: $67-78$

Walker, J., Crowley, P., Moreman, A.D., BArrett, J. (1993): Biochemical properties of cloned glutathione-Stransferase(s) from Schistosoma mansoni and Schistosoma japonicum. Mol. Biochem. Parasitol., 61: 255 - 254

Zhao, T. J., Singhal, S. S., PiPer, T. J., Cheng, J. Z., Pandya, U., Clark-Wronski, J., Awasthi, S. And AWASTHI, Y. C. (1999): The role of human glutathione Stransferases hGSTA1-1 and hGSTA2-2 in protection against oxidative stress. Arch. Biochem. Biophys., 367: 216-224 